\title{
Possibilidades da CIF no contexto das Altas habilidades/Superdotação
}

\author{
Autores: André de Souza Rocha ${ }^{1}$; Ananda Ludwig Burin²; Aline Mendes ${ }^{3}$
}

1. Fisioterapeuta do Centro de Reabilitação Ana Maria Philippi - CENER; Articulador de Pesquisa do Núcleo de Estudos e Pesquisas - NESPE; Fundação Catarinense de Educação Especial FCEE.

http://lattes.cnpq.br/2661547964572512

2. Professora de Matemática do Núcleo de Altas Habilidades/Superdotação $\mathrm{NAAH} / \mathrm{S}$; Fundação Catarinense de Educação Especial FCEE.

http://lattes.cnpq.br/3927288556773114

3. Psicóloga do Núcleo de Altas Habilidades/Superdotação - NAAH/S; Fundação Catarinense de Educação Especial FCEE.

http://lattes.cnpq.br/9369228158874271

\section{Editorial}

A Classificação Internacional de Funcionalidade, Incapacidade e Saúde CIF é um modelo para a organização e documentação de informações sobre funcionalidade e incapacidade ${ }^{1}$. Ela conceitualiza a funcionalidade como uma "interação dinâmica entre a condição de saúde de uma pessoa, os fatores ambientais e os fatores pessoais" através de um modelo biopsicossocial, relevante para obtenção de indicadores sobre a funcionalidade humana ${ }^{2}$. A partir de sua publicação pela Organização Mundial de Saúde - OMS em 20011 e tradução para português em $2003^{3}$, diversas iniciativas nas áreas de políticas públicas vêm direcionando o seu uso nos sistemas de saúde, assistência social e educação em nível nacional e internacional ${ }^{4-7}$. Com a apropriação e estudo de seus conceitos na área da educação, surgem novas perspectivas de aplicação e possibilidades de atualização da CIF. Nesse sentido, a funcionalidade de crianças com Altas Habilidades/Superdotação (AH/SD) representa um desafio à CIF no momento em que o modelo biopsicossocial apresentado parece não alcançar, ou mesmo não contemplar, a funcionalidade acima daquela considerada como padrão para a população em geral. Este editorial irá discutir as possibilidades de aplicação da CIF na análise da funcionalidade de crianças e jovens com AH/SD e apresentar uma proposta de ampliação dos qualificadores que possam abranger esse contexto.

Segundo Renzulli ${ }^{8,9}$ e Smedsrud ${ }^{10}$, o conceito ampliado de altas habilidades vai além da inteligência elevada e aborda o talento diferenciado dentro de uma perspectiva mais alinhada com as altas competências funcionais de um indivíduo. Nesse conceito são descritas as pessoas que demonstram potencial elevado em qualquer uma das seguintes áreas, isoladas ou combinadas: intelectual, acadêmica, liderança, psicomotricidade e artes, além 
de apresentar grande criatividade, envolvimento na aprendizagem e realização de tarefas em áreas de seu interesse ${ }^{8-11}$.

Assim, indivíduos com AH/SD são aqueles que, quando comparados a seus pares (aqueles de mesma área de habilidade e interesse) apresentam habilidade significativamente superior em uma ou em mais de uma área do conhecimento, além de apresentarem envolvimento com tarefas e facilidade de aprendizado (quando dentro de sua área de interesse), pensamento criativo e curiosidade ${ }^{8-10}$. Dados da OMS estimam que de 3,5 a 5\% da população mundial possuem escores superiores em testes tradicionais de QI, o que representa apenas pessoas com AH/SD em uma ou mais áreas acadêmicas ${ }^{12}$. Ao incluirmos outras áreas do conhecimento como liderança, psicomotricidade e artes esse percentual aumenta significativamente para 15 a $30 \%$ da população mundial ${ }^{11}$.

Este representativo contingente de pessoas não receberia, atualmente, qualquer análise diferenciada de sua funcionalidade elevada ao considerarmos o esquema de qualificadores proposto na CIF. Os qualificadores nos componentes de funcionalidade e incapacidade direcionam apenas à manutenção ou perda em um determinado construto de saúde. Deste modo, a funcionalidade de pessoas com indicadores de AH/SD a partir da CIF não será compatível com a condição desses sujeitos que se encontram acima da capacidade de descrição dos qualificadores. Tendo em vista a forma como estão propostos, a partir de escala negativa, não há previsibilidade para funcionamentos acima da média.

De forma objetiva, os capítulos de Funções Mentais (b1) e Aprendizagem e aplicação de conhecimento (d1) seriam os principais pontos de partida para a codificação de crianças e jovens com altas habilidades. No entanto, conforme abordado anteriormente, a natureza da qualificação destes códigos somente permite, ainda, a possibilidade de direcionar a "perda" de saúde. Nesse sentido, no âmbito das $\mathrm{AH} / \mathrm{SD}$, poderia ser adotado o mesmo conceito positivo relativo à qualificação dos códigos de Fatores Ambientais, que permitem indicar se os aspectos do ambiente atuam como facilitadores (e+, escala positiva) ou barreiras (e., escala negativa). A própria CIF em seu Anexo 2 descreve que "a critério do usuário, podem ser desenvolvidas escalas de codificação para indicar os aspectos positivos da funcionalidade" ${ }^{1}$. Assim sendo, os qualificadores poderiam ser descritos de forma similar à escala de facilitadores, adequando-se a nomenclatura de acordo com o componente codificado: $\mathbf{x x x + 0}$

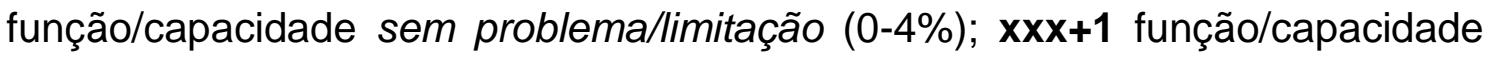
levemente elevada (5-24\%); função/capacidade moderadamente elevada (2549\%); xxx+3 função/capacidade consideravelmente elevada (50-95\%); xxx+4 função/capacidade completamente elevada $\quad(96-100 \%) ; \quad \mathbf{x x x + 8}$ função/capacidade elevada não especificada.

A possibilidade de ampliar esse modelo de qualificação positiva para os códigos de Funções Mentais (b1) e Aprendizagem e aplicação de conhecimento (d1), permitiria a descrição da alta habilidade, criatividade e liderança em uma 
ou mais áreas da funcionalidade desses indivíduos. Por exemplo, uma criança capaz de Aprender a calcular (d150) ou Calcular (d172) em um tempo significativamente inferior comparativamente aos seus pares (a maioria das crianças realizou essas atividades em 60 minutos, enquanto a criança realizou em 10 minutos, muito menos da metade do tempo que os demais) seria codificada apenas como d150.0 e d172.0 (ambos nenhuma limitação). Porém, na realidade, ela tem uma habilidade acima da média para desempenhar essas atividades de raciocínio e execução matemáticos. Esse talento certamente teria impacto sobre as avaliações contemplando as Funções intelectuais (b117) e as Funções de cálculo (b172). Sendo assim, caso houvesse a possibilidade de codificação positiva, ela poderia receber os códigos $1150+4$ e $d 172+4$ (ambos capacidade completamente elevada) ou seja, uma capacidade até $100 \%$ acima da média para essas atividades, conforme o esquema quantitativo dos qualificadores. Além disso, os códigos de Funções mentais (b1) também poderiam ser qualificados de forma positiva, mesmo na ausência de um teste padronizado (por exemplo b117+8 e b172+8, função elevada não especificada).

Tomando esse mesmo conceito, na análise da funcionalidade de crianças com extrema habilidade motora e talento para execução de movimentos muito acima da capacidade das demais crianças, nas possibilidades atuais da CIF, as mesmas poderiam ser somente qualificadas em suas Funções psicomotoras como b147.0 (nenhum problema) e em sua capacidade para Aquisição de habilidades como d155.0 (nenhuma limitação). Mais uma vez, a adequação dos qualificadores para uma escala positiva nos moldes dos capítulos de Fatores Ambientais, permitiria uma codificação mais coerente com a real funcionalidade dessas crianças, por exemplo b147+8 (função elevada não especificada) e d155+4 (capacidade completamente elevada), este último em casos em que os testes de habilidade motora tenham demostrado uma capacidade $100 \%$ superior as demais, na mesma idade e sexo.

Conforme abordado previamente, as habilidades nos domínios da criatividade e liderança são componentes importantes na análise do desempenho de atividades que indiquem se uma criança ou jovem tem um talento diferenciado ${ }^{8,9}$. Ao se analisar a habilidade de tocar um instrumento musical, esses aspectos da funcionalidade poderiam, também, ser descritos no escopo da CIF adotando-se a mesma lógica de escala positiva de qualificadores dos Fatores Ambientais. Neste caso, a habilidade poderia ser descrita no contexto das Funções mentais de sequenciamento de movimentos complexos (b176) relacionadas a Aquisição de habilidades (d155) para tocar um dado instrumento (Arte e cultura - d9202). Crianças que apresentam destacada maestria nesses componentes, no sentido de demonstrar o aprendizado do instrumento musical de maneira muito acima do esperado, teriam códigos variando de $d 155+8$ a $d 155+4$ ao invés de simplesmente receber d155.0 (nenhuma limitação em adquirir habilidades). Esse mesmo aspecto poderia ser aplicado aos comportamentos que indicam uma capacidade elevada de 


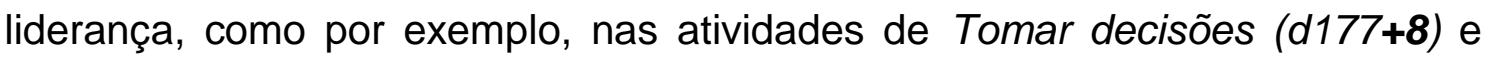
Lidar com o estresse e outras demandas psicológicas (d240+8).

Outro ponto relevante a ser debatido envolve a temática das crianças que apresentam dupla excepcionalidade. São indivíduos que possuem alguma deficiência/transtorno e ao mesmo tempo um desempenho acima da média em alguma área, ou seja, possuem capacidade superior em alguma área do desempenho humano concomitante a outras condições como: dislexia, disgrafia, desordens psiquiátricas, deficiências físicas e sensoriais, déficit no processamento central, déficit de atenção e hiperatividade (TDAH), transtorno de espectro autista (TEA) ${ }^{13,14}$. Nesse caso é possível uma criança com TEA apresentar uma restrição nas Interações interpessoais básicas (d710.8) e ser capaz de concentrar grande nível de atenção em um exercício de cálculo de maneira muito superior comparativamente aos seus pares (Concentrar a atenção - d160 e Calcular - d172). A possibilidade de aplicar um qualificador positivo a estes componentes de Atividade e Participação permitiria identificar a dupla

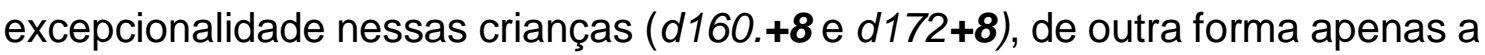
ausência de limitação poderia ser qualificada (d160.0 e d172.0).

Tendo em vista o exposto, torna-se de grande relevância a discussão sobre a possibilidade de ampliação do alcance da CIF para inclusão das altas habilidades. Os desdobramentos da inserção de qualificadores positivos podem possibilitar o uso da CIF como triagem ou rastreio de crianças com indicadores de precocidade e/ou indicadores de AH/SD elegíveis para avaliação de tais indicadores. Conforme os diversos exemplos de aplicação discutidos neste editorial, a proposta de incorporar ao modelo biopsicossocial os qualificadores positivos nos demais componentes da CIF, além dos Fatores Ambientais, têm um grande potencial para direcionar possíveis encaminhamentos para programas que possam avaliar as singularidades e características das AH/SD. Esta ação irá oportunizar a essas crianças abordagens educacionais e de saúde mais assertivas. A identificação precoce da alta funcionalidade, traduzida em um talento diferenciado, tem um impacto positivo no futuro destas crianças que poderão contribuir para a sociedade ao desempenhar papéis destacados como acadêmicos, pesquisadores, atletas de alto rendimento, reconhecidos artistas e lideranças empreendedoras e sociais ${ }^{9}$.

De acordo com os Anexos 7 e 8 da CIF 1, a classificação está em aperfeiçoamento e revisão constantes e a proposição aqui apresentada visa contribuir para esse processo, trazendo à tona o debate sobre a funcionalidade elevada. Além disso, a iniciativa de conferir maior abrangência à CIF, permitindo a análise das especificidades das pessoas com AH/SD, irá estimular seu uso no cenário educacional e adicionar possibilidades de aplicação principalmente na área da educação especial. 


\section{Referências}

1. WHO. International Classification of Functioning, Disability and Health. Geneva: World Health Organization, 2001.

2. WHO. How to use the ICF: A practical manual for using the International Classification of Functioning, Disability and Health (ICF). Exposure draft for comment. Geneva: World Health Organization, 2013.

3. Organização Mundial da Saúde. Classificação Internacional de Funcionalidade, Incapacidade e Saúde. OMS - OPAS e Ed da Univ São Paulo 2004; 238.

4. Brasil. Lei 13.146, de 6 de julho de 2015. Institui a Lei Brasileira de Inclusão das Pessoas com Deficiência (Estatuto da Pessoa com Deficiência). Diário Oficial da União 2015; 7 jul., http://www.planalto.gov.br/ccivil_03/_ato2015-2018/2015/lei//13146.htm (2015, accessed 18 December 2019).

5. Castro S, Palikara O. An Emerging Approach for Education and Care: Implementing a Worldwide Classification of Functioning and Disability Edited. New York: Routledge, 2018. Epub ahead of print 2018. DOI: 10.4324/9781315519692.

6. De Miranda-Correia L. Special education in Portugal: The new law and the ICF-CY. Procedia - Soc Behav Sci 2010; 9: 1062-1068.

7. Hollenweger J. Development of an ICF-based eligibility procedure for education in Switzerland. BMC Public Health 2011; 11: S7.

8. Renzulli JS. The three-ring conception of giftedness: A developmental model for promoting creative productivity. 2005. Epub ahead of print 2005. DOI: $10.1017 /$ CBO9780511610455.015.

9. Renzulli JS. Reexamining the Role of Gifted Education and Talent Development for the 21st Century: A Four-Part Theoretical Approach. Gift Child Q 2012; 56: 150-159.

10. Smedsrud J. Explaining the variations of definitions in gifted education. Nord Stud Educ 2020; 40: 79-97.

11. Virgolim AMR. Altas habilidade/superdotação: encorajando potenciais. Brasilia: Ministério da Educação, Secretaria de Educação Espeial, 2007.

12. Pérez SGPB. Mitos e Crenças sobre as Pessoas com Altas Habilidades: alguns aspectos que dificultam o seu atendimento. Revista Educação Especial 2003; 1: 45-59.

13. Roama-Alves RJ, Nakano T de C. Dupla excepcionalidade: Altas habilidades/Superdotação nos transtornos neuropsiquiátricos e deficiências. SãoPaulo: Vetor, 2021.

14. Ronksley-Pavia M. A Model of Twice-Exceptionality. J Educ Gift 2015; 38 : 318-340. 